\title{
Perspectives on perceived stigma and self-stigma in adult male patients with depression
}

\author{
This article was published in the following Dove Press journal: \\ Neuropsychiatric Disease and Treatment \\ 29 July 2014 \\ Number of times this article has been viewed
}

\section{Klara Latalova \\ Dana Kamaradova \\ Jan Prasko}

Department of Psychiatry, Faculty of Medicine and Dentistry, University

Palacky Olomouc, Olomouc,

Czech Republic
Correspondence: Klara Latalova Department of Psychiatry, Faculty of Medicine and Dentistry, Palacky University Olomouc, Olomouc University Hospital, IP Pavlova 6, Olomouc 77500, Czech Republic

Email klaralat@centrum.cz
Abstract: There are two principal types of stigma in mental illness, ie, "public stigma" and "self-stigma". Public stigma is the perception held by others that the mentally ill individual is socially undesirable. Stigmatized persons may internalize perceived prejudices and develop negative feelings about themselves. The result of this process is "self-stigma". Stigma has emerged as an important barrier to the treatment of depression and other mental illnesses. Gender and race are related to stigma. Among depressed patients, males and African-Americans have higher levels of self-stigma than females and Caucasians. Perceived stigma and self-stigma affect willingness to seek help in both genders and races. African-Americans demonstrate a less positive attitude towards mental health treatments than Caucasians. Religious beliefs play a role in their coping with mental illness. Certain prejudicial beliefs about mental illness are shared globally. Structural modeling indicates that conformity to dominant masculine gender norms ("boys don't cry") leads to self-stigmatization in depressed men who feel that they should be able to cope with their illness without professional help. These findings suggest that targeting men's feelings about their depression and other mental health problems could be a more successful approach to change help-seeking attitudes than trying to change those attitudes directly. Further, the inhibitory effect of traditional masculine gender norms on help-seeking can be overcome if depressed men feel that a genuine connection leading to mutual understanding has been established with a health care professional.

Keywords: stigma, self-stigma, depression, male gender

\section{Introduction}

Social stigma is the extreme disapproval of a person or group regarding various characteristics that distinguish an individual from other members of a society. Social stigma can result from the perception of mental illness, as well as various other characteristics, such as skin color, ethnicity, and sexual orientation.

There are two principal types of stigma in mental illness, ie, "public stigma" and "self-stigma". ${ }^{1}$ The public stigma is the perception held by others that the mentally ill individual is socially undesirable. The perceptions of mental illness by others lead to stigmatizing attitudes, prejudices, and actions by patients' families and members of their community, sometimes including health care professionals.

Information obtained in open-ended discussions involving individuals with a personal knowledge or history of depression indicate that the messages delivered by family and friends made them feel labeled, judged, lectured to, and rejected. ${ }^{2}$

Stigmatized persons may internalize perceived prejudices and develop negative feeling about themselves. The result of this process is self-stigma. Self-stigma is manifested by decreased self-esteem and increased depression. Patients feel shame and embarrassment about having a mental illness. These feelings limit social interactions 
and impair occupational functioning. When a patient labels himself/herself as a person in need of treatment, this may lead to further reduction of self-esteem, which constitutes the self-stigma of seeking help. Thus, there are two subgroups of self-stigma, ie, one related more directly to experiencing mental illness and the other linked to seeking treatment. Recent research suggests that these two constructs are related but independent of each other. ${ }^{3}$

Stigma has emerged as an important barrier to the treatment of depression, ${ }^{4}$ schizophrenia, ${ }^{5}$ panic disorder, ${ }^{6}$ bipolar disorder, ${ }^{7}$ and post-traumatic stress disorder. ${ }^{8,9}$ Self-stigma is associated with a negative attitude towards seeking treatment ${ }^{10,11}$ and treatment adherence. ${ }^{5}$

Help-seeking behavior is affected by gender. One of the first things that male children are taught is that "boys don't cry". ${ }^{12}$ Cultural influences result in differences between boys' and girls' attitudes when they formulate a request for help. ${ }^{13}$ The role of cultural discourse in producing normative and marginalized masculinities in adolescents was explored. ${ }^{14}$ Practices of heterosexuality, homophobia, athleticism, economic privilege, toughness, and violence provided pathways toward achieving and/or maintaining status as the hegemonic masculine norm in adolescence. ${ }^{14}$ Masculinity, as understood in most Western societies, is manifested by stoic endurance of suffering, self-reliance, and unwillingness to seek help. This gender role, learned early in life and later enhanced by experiences such as military service, is difficult to change. However, as mentioned above, the effect of gender role on resistance to help-seeking is mediated, at least to some extent, by self-stigma, in that persons with mental illness, believe themselves to be inferior or "weaklings" for needing to seek treatment. Self-stigmatization of seeking help is more pronounced in men than in women. ${ }^{15,16}$ Self-stigmatization is probably more amenable to intervention than public stigma or traditional gender roles.

Depression is associated with public stigma as well as self-stigma. Patients reason that "only weak people get depressed. If I am depressed, I am weak" ${ }^{4}$ Public stigma is expressed by opinions that depressed patients are dangerous, and that they should "pull themselves together". ${ }^{17}$

In summary, stigmatization is a major problem interfering with treatment in patients with mental illness, and is more pronounced in men. The main purpose of this review is to examine its impact on help-seeking in relation to depression in men.

\section{Methods}

Relevant studies were identified through the PubMed, Medline, Web of Science, and Scopus databases as well as existing reviews. The search terms used included "depression", "stigma", "self-stigma", and "gender". The search was performed by repeated use of these words in different combinations without language or time constraints. Articles on children were not included. The articles were collected, sorted by their relevance, and key articles in reference lists were searched. Reference lists of publications identified by these procedures were enriched by manually tracing the relevant citations.

\section{Results}

\section{Assessment of perceived stigma}

The Perceived Devaluation-Discrimination scale ${ }^{18}$ has 12 items. Participants rate from 1 (strongly agree) to 6 (strongly disagree) statements about how people view current (or former) psychiatric patients. "Most people would not hire a former mental patient to take care of their children, even if she had been well for some time" is an example of an item.

A depression stigma scale was constructed by Griffiths et al for the purpose of a study designed to examine the effect of Internet information on depression stigma. ${ }^{19}$ The scale has a total of 18 items, with "personal stigma" and "perceived stigma" assessed by nine items each. "Personal stigma" reflects the individual's personal attitudes, whereas "perceived stigma" reflects the individual's belief about the attitudes of others. "Depression is a sign of personal weakness" is an example of an item assessing personal stigma. The analogous item assessing perceived stigma is "most people believe that depression is a sign of personal weakness". The "personal stigma" is equivalent to self-stigma if the respondent is depressed.

\section{Assessment of self-stigma}

Self-stigma is assessed by the Internalized Stigma of Mental Illness Scale. ${ }^{20}$ This scale focuses on the patient's subjective experience by offering for endorsement statements like "I am embarrassed and ashamed to have mental illness". ${ }^{10}$

The Self-Stigma of Seeking Help Scale is a 10-item instrument using a 5-point Likert-type scale to assess agreement or disagreement with statements like "it would make me feel inferior to ask a therapist for help". ${ }^{21}$ Researchers assessed for the presence or absence of stigma by asking about items in a clinical vignette that is read to the patient. ${ }^{22}$

\section{Self-stigma, depression, race, and gender}

A Canadian study aimed to identify factors associated with stigma related to depression in a probability sampled population-based survey of 3,047 adults, 2,557 (958 men and 1,599 women) of whom participated in multivariate 
regression analysis. ${ }^{23}$ Computer-assisted telephone interview was used to assess personal depression stigma, depression literacy, lifetime major depression, and demographics. Personal depression stigma (or self-stigma) was assessed using the Griffiths scale described above. ${ }^{19}$

Men had higher stigma scores (mean 12.7, 95\% confidence interval 12.4-13.0) than women (mean 10.0, 95\% confidence interval 9.7-10.3; $P<0.001)$. In multivariate regression models, better information about depression (depression literacy) was associated with lower stigma scores, regardless of gender. Endorsing doctors and medications as the best help for depression was negatively associated with stigma in women. In men, endorsing family/friends as the best help for depression was positively associated with stigma scores.

In the authors' opinion, higher levels of self-stigmatization can be expected in men generally, because men are more likely want to achieve higher positions at work than women; depressed men are confronted with the fact that they are unable to meet their goals. On the other hand, a study of 1,229 patients with schizophrenia in 14 European countries demonstrated higher levels of self-stigmatization in women. ${ }^{24}$ Similar results were reported elsewhere. ${ }^{25}$ However, another study were unable to confirm any gender differences in self-stigmatization. ${ }^{26}$

Self-stigma (labeled as "internalized stigma") and public stigma were assessed in a representative sample of 248 (207 women) Caucasian and African-American adults older than 60 years who were depressed. ${ }^{10}$ The subjects were surveyed by telephone. The African-Americans showed significantly higher levels of self-stigmatization $(t[246]=-2.118$, $P=0.035$ ) with a small to medium effect size (Cohen's $d=0.26$ ) than the Caucasian subjects. They also demonstrated less positive attitudes toward seeking mental health treatment. Analyses showed that self-stigma partially mediated the relationship between race and attitudes toward treatment. ${ }^{10}$

A study investigating the beliefs of older AfricanAmericans about depressive symptoms and factors associated with willingness to use mental health services recruited a total of 153 senior center members (56 male and 97 female) 55 years and older. ${ }^{22}$ Using a depression vignette, participants indicated if the person was depressed and their endorsement of items reflecting beliefs, stigma, symptom management, and willingness to use treatments. A questionnaire assessed current symptomatology.

Depression symptoms (mostly mild) were reported by $24.2 \%$ of the participants. Most subjects endorsed active treatments, preference for treatment in physician and therapist offices, and willingness to take medications. Among the items reflecting stigma, $28.9 \%$ of subjects agreed with the statement that depression is a "sign of personal weakness", $27.5 \%$ would be "scared that others would find out about their illness", but 33.3\% "would feel okay if community knew". Logistic regression indicated that "feeling okay if community knew of depression diagnosis" was one of the items associated with willingness to see a physician if feeling depressed. Associations between predictors and willingness to seek treatment were affected by the participants' gender and clinical status (depressed or not). ${ }^{22}$

A study designed to examine African-Americans' beliefs about mental illness, attitudes towards seeking help, and coping behaviors surveyed 272 community-dwelling subjects (58\% men). ${ }^{27}$ The age range was $25-72$ years. Depression was the most common mental illness detected.

The Inventory of Attitudes Toward Seeking Mental Health Services ${ }^{28}$ was one of the tools used. This instrument consists of three subscales, ie, psychological openness, helpseeking propensity, and indifference to stigma. Psychological openness indexes the extent to which persons are open to an acknowledgement of mental health problems. The items assessing indifference to stigma are largely probing selfstigma, for example "having been mentally ill carries with it a burden of shame". Women showed greater psychological openness $(P<0.03)$ and greater willingness to seek mental health services $(0.02)$ than men. The level of indifference to stigma was unrelated to age, gender, and diagnosis of mental illness. A rating scale was used to assess preferred coping style. The results indicated that while the subjects were open to seeking mental health services, they prefer religious coping. ${ }^{27}$

A major effort to identify the core public sentiments underlying misinformation, prejudice, and discrimination associated with mental illness was based on data from 16 countries with different ethnic composition providing nationally representative samples of noninstitutionalized adult respondents to a survey of stigma. ${ }^{29} \mathrm{~A}$ total of 6,542 and 6,539 respondents received schizophrenia and depression vignettes, respectively. After reading the vignette, each respondent was invited to endorse 16 items tapping information about mental illness (stigma as a lack of knowledge), and 27 items tapping various types of prejudice (stigma as social rejection and devaluation).

The results demonstrated improving knowledge about causes and treatment of mental illness. However, the data regarding stigma as social rejection and devaluation were less reassuring. The greatest amount of negative response to the mentally ill was concerned with issues that deal primarily with intimate setting (the family). Thus, the most frequently endorsed negative statements were that the 
mentally ill should not teach children, were not welcome as in-laws, were unpredictable, were likely to be violent to self, and should not care for children. These endorsements applied to both schizophrenia and depression vignettes, and, with some regional variation, to all participating countries. These core sentiments underlying rejection and intolerance, the "backbone of stigma", should be targeted in future public information campaigns aimed at reduction of stigma.

An important study covering 16 countries and many ethnic groups identified the core public sentiments underlying the stigma of mental illness. Although there were some regional variations, these sentiments were shared globally. Self-stigmatization is frequently related to deep lifelong feelings of inferiority that were compensated for by diligence, carefulness, helping others, or other compensatory behaviors. Being labeled with a psychiatric diagnosis directly impacts the patient's fragile self-concept. Self-stigmatization is sometimes defined as an identity transformation that may lead to a reduction of self-confidence. ${ }^{30}$ Reduced self-confidence may in turn result in a tendency to perceive the behavior of others as discriminatory, when in fact it may not be so.

Clinical experience suggests that patients with premorbid obsessive or paranoid personality features are more likely to self-stigmatize. A review and meta-analysis of 45 controlled studies reported relations between self-stigma and psychosocial factors such as hope and self-confidence. There was also a correlation with symptom severity and with negative attitude to treatment. ${ }^{31}$

Outpatients who internalized prejudices against psychiatric patients were less likely to believe in an improvement of their mental state, were more depressed, and showed negative self-appraisal..$^{32}$ Individuals with higher levels of self-stigmatization preferred avoidant strategies in coping with stress, such as giving up prematurely or finding courage via habit forming drugs. At the same time, they were less able to plan responses to unpleasant situations and to use such experiences as opportunities for personal growth.

In summary, gender and race are related to stigma. Studies conducted in North America indicated that men and African-Americans have higher levels of self-stigma than women and Caucasians. Perceived stigma and self-stigma affect willingness to seek help in both genders and races. African-Americans demonstrate a less positive attitude towards mental health treatments than Caucasians. Religious beliefs play a role in their coping with mental illness, and some patients may view religious practices as an alternative to mental health treatments offered by the medical establishment.

\section{Modeling relationships between perceived stigma, self-stigma, masculinity, depression, and help-seeking}

Studies reporting the direct or zero-order relationships among masculinity, self-stigma, help-seeking attitudes, and other variables have provided important insights. However, the relationships between these variables are complex. Multifaceted models using structural equations represent a suitable approach to improving our understanding of complexity.

The mediating effects of the self-stigma on the link between perceived public stigma and willingness to seek psychological counseling was examined using data from 676 undergraduate students ( 339 women and $337 \mathrm{men}$ ). ${ }^{15}$ Perceived stigma was assessed using the Perceived DevaluationDiscrimination scale. ${ }^{18,33}$ Self-stigma was measured with the Self-Stigma of Seeking Help Scale. ${ }^{21}$ Attitudes toward seeking professional help and willingness to seek counseling were assessed with other scales.

Structural equation modeling of the data from the complete sample indicated that the link between perceived public stigma and willingness to seek counseling was fully mediated by self-stigma and attitudes. Perceptions of public stigma contributed to the experience of self-stigma, which, in turn, influenced help-seeking attitudes and eventually willingness to seek help. Basic features of this model are included in our combined model depicted in Figure 1.

To explore the effect of gender, separate models were computed for women and men. The results showed that the relationship between perceived stigma and self-stigma was present in both genders, but it was stronger in men.

Structural equation modeling was used in a study that examined three mediators in the link between gender role conflict and willingness to seek psychological counseling. ${ }^{34}$ The subjects were 575 male students. Gender role conflict was assessed by a scale that measured the negative consequences associated with male gender role socialization. The mediators were self-stigma (assessed with the Self-Stigma of Seeking Help Scale), tendency to disclose distressing information, and attitudes toward seeking counseling. Results showed that the link between gender role conflict and willingness to seek counseling was partially mediated by each of these three factors. Subjects with greater gender role conflict were more likely to self-stigmatize and less likely to self-disclose. High self-stigma and less disclosure then led to less positive attitudes and, in turn, to less willingness to seek counseling.

Building on the previously published model of the relationships between gender role conflict and willingness to seek counseling, ${ }^{34}$ a study aimed to expand that approach and 


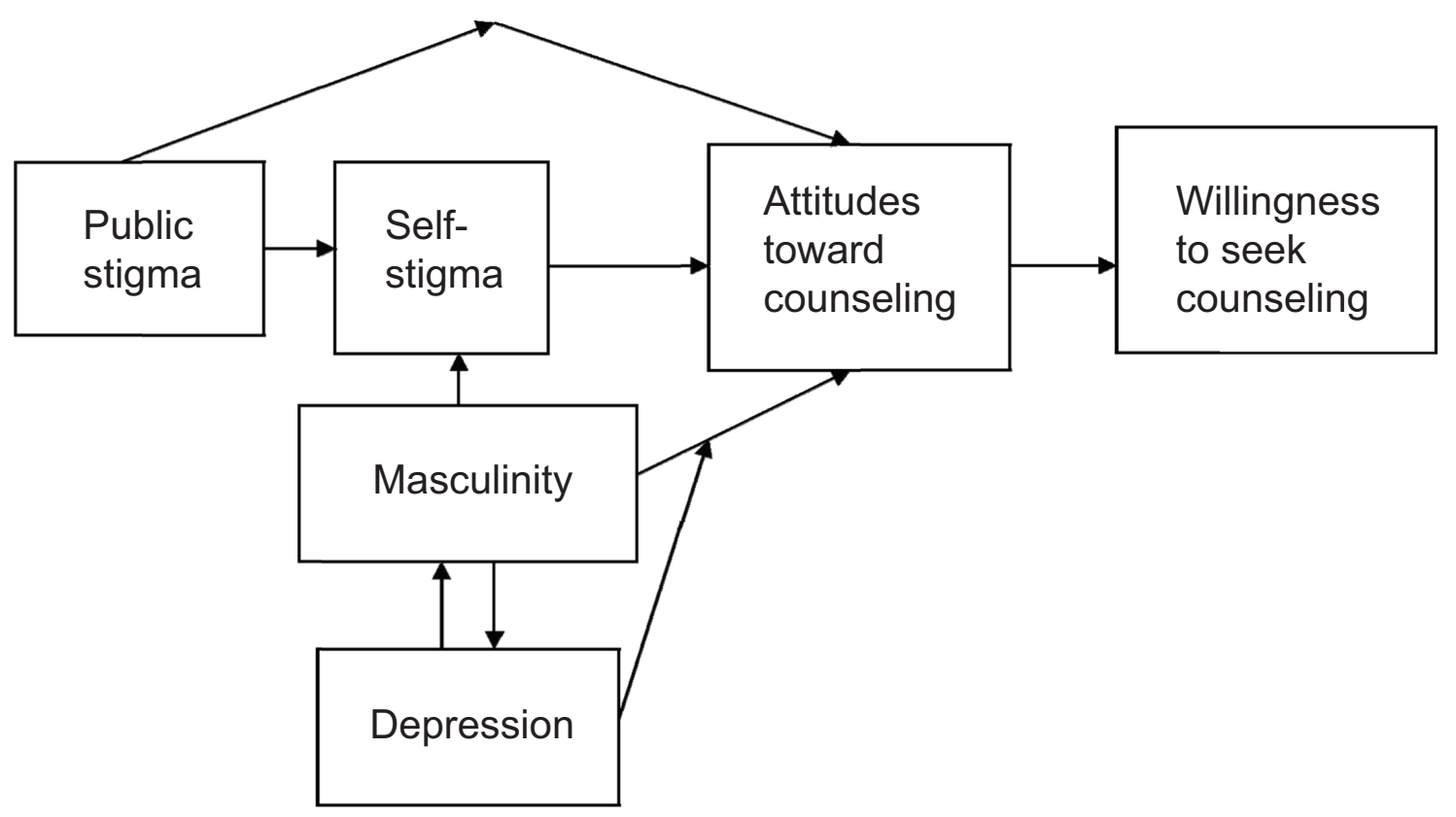

Figure I Stigma, masculinity, depression, and willingness to seek help in men. Model of the relationship between variables affecting attitudes and willingness to seek counseling. Effects of public stigma and masculinity are partially mediated by self-stigma. Depression moderates the relationship between masculinity and attitudes toward counseling. The model combines the salient features of four published models obtained by structural equations. ${ }^{\mid 2,15,34,35}$

examine its cross-cultural relevance in a sample 4,773 men from both majority and other populations. ${ }^{12}$ The subjects were recruited and surveyed via the Internet. The majority were European-Americans (72.7\%). There were $10 \%$ of AsianAmericans, 7.3\% Latino-Americans, and 4.7\% African-Americans. Participants identified as heterosexual (82.4\%) or gay (6.8\%). Most subjects said they were not depressed (54.2\%), and $45.8 \%$ said that they were currently depressed.

Self-stigma was assessed with the Self-Stigma of Seeking Help Scale, while other instruments measured the conformity to dominant masculine gender norms (masculinity), attitudes toward counseling, and depression. Significant differences between ethnicities as well as between sexual orientations were found for means for masculinity and self-stigma. A structural model indicated that increased masculinity was associated with negative attitude toward counseling, and this effect was partially mediated by self-stigma. Depression appeared as a moderator of masculinity, self-stigma, and attitudes toward counseling.

In a follow-up analysis, some group differences emerged. For example, the relationship between masculinity and self-stigma was weaker for African-American men than European-American men. Heterosexual men showed a stronger association between masculine norms and selfstigma than gay men. ${ }^{12}$

Although Vogel et al examined the effects of different ethnicities and sexual orientations in their sample of 4,773 men, ${ }^{12}$ they did not focus on several potentially important demographic factors. This was done in subsequent re-analysis of the same sample by Hammer et al ${ }^{11}$ as in Vogel et al. ${ }^{12}$ Self-stigma was assessed with the Self-Stigma of Seeking Help Scale, other instruments measured the conformity to dominant masculine gender norms (masculinity), attitudes toward counseling, and depression. Furthermore, community size, education, and income level were established for each participant.

Similar to Vogel et al, ${ }^{12}$ structural equation modeling analyses suggested that, across all male subgroups, masculinity was associated with self-stigma and, in turn, with attitudes toward counseling. However, the relationship between masculinity norms and self-stigma was twice as strong for rural men than for other men. The level of education also exerted some effects on the relationship between masculinity and self-stigma.

The model published by Vogel et al ${ }^{12}$ used the conformity to dominant masculine gender norms as a measure of masculinity. In a subsequent study, Levant et al used instead a measure of traditional masculine ideology as a measure of masculinity. ${ }^{35}$ Masculinity, selfstigma, ${ }^{21}$ depression, attitude towards seeking help, and other variables were assessed using an online survey in a nonclinical sample of 654 men recruited by advertisements. Moderated path analysis was used. The principal results showed that high levels of masculinity were associated with negative attitude towards seeking help, and this effect was partly direct, partly mediated by self-stigma. 
Depression acted as a moderator of these effects, such that higher levels of depression were associated with greater effects of masculinity on positive attitude towards seeking help. Additional moderators were also contributing. Thus, this study, ${ }^{35}$ using a different sample and a different measure of masculinity, replicated the basic features of the model published by Vogel et al. ${ }^{12}$ To simplify understanding and a synthesis of the results of work using structural equation modeling, Figure 1 shows a combined model that includes the salient features of the published studies of this type. ${ }^{12,15,34,35}$

\section{Discussion}

The results reviewed in preceding sections suggest that in order to remediate negative attitude toward seeking help in men, preventive psychosocial interventions should target self-stigma. Targeting men's feelings about their depression and other mental problems could be a more successful approach to change their help-seeking attitude than trying to change that attitude directly. ${ }^{35}$ However, we should keep in mind that these results were obtained in individuals who were not depressed, or who had mild depressive symptoms. These models await replication in patients who are clinically depressed. Furthermore, the literature suggests that gender differences related to stigma should be considered in the treatment of patients with depression.

Improved information about depression (depression literacy) was associated with less stigma. ${ }^{23}$ It is possible that this association reflects a causal relationship. Testing this proposition experimentally, a British study aimed to test the efficacy of educational interventions for reducing the stigma associated with depression in a randomized controlled trial. ${ }^{19}$ A sample of 525 individuals with elevated scores on a depression assessment scale were randomly allocated to a depression information website, a cognitive-behavioral skills training website, or an attention control condition. Personal stigma (personal stigmatizing attitudes to depression, equivalent to self-stigma if respondent is depressed) and perceived stigma were assessed before and after the intervention. The Perceived Devaluation-Discrimination scale $^{18}$ and Internalized Stigma of Mental Illness Scale were used. ${ }^{20}$

The exposure to internet sites significantly reduced personal stigma in comparison with control, although the effects were small. The depression information site had no effect on perceived stigma and the cognitive-behavioral site was associated with a small increase in perceived stigma relative to the control. Changes in stigma were not mediated by changes in depression literacy, or cognitive-behavioral therapy literacy. Recipients of cognitive-behavioral therapy showed a reduction in personal stigma, but this effect was not mediated by decreased depressive symptoms.

Although the inhibitory effects of various aspects of masculinity on self-stigma and help-seeking have been clearly demonstrated in quantitative studies of large samples of men, there are important variables affecting this relationship that emerge in less formal research approaches to the problem. A qualitative study of discourses of help-seeking used a semistructured interview of 38 men with depression, either formally diagnosed or self-reported. ${ }^{36}$ Several insights in the form of discursive frames regarding help-seeking in depression emerged; one of these frames was labeled "genuine connection". If the men felt that a genuine connection leading to mutual understanding has been established with a health care provider, they were willing to talk openly and in detail about their depression. "In this frame the traditional masculine, scientific model of being fixed with medication (a business approach) paled amid the emergence of more traditional feminine features, such as being understood and listened to in the context of a trusting, personal relationship.." ${ }^{36}$ The value of this insight for clinical care of depressed men is obvious.

\section{Conclusion}

Stigma, and particularly self-stigma, is increasingly recognized as a barrier to the treatment of numerous mental disorders. The inhibitory effect of self-stigma on helpseeking is especially expressed in Caucasian depressed males, but it is also detectable in Caucasian females and in African-Americans of both genders.

Emerging evidence suggests that disseminating public information about depression may prevent or reduce selfstigma. Educating patients and their families about mental illness, particularly depression, will help them understand that seeking help is not a sign of weakness. This approach requires more time and effort than care limited to prescribing medications, but it has a better chance of long-term success since it improves the patient's insight. Future research should use longitudinal prospective designs to study the effectiveness of psychoeducation in improving insight on treatment seeking and treatment adherence, including adherence to medication.

\section{Acknowledgment}

This research was supported by a grant from the Czech Ministry of Health (IGA MZ CR NT11047-4).

\section{Disclosure}

The authors report no conflicts of interest in this work. 


\section{References}

1. Corrigan P. How stigma interferes with mental health care. Am Psychol. 2004;59:614-625.

2. Fernandez YG, Duberstein P, Paterniti DA, Cipri CS, Kravitz RL, Epstein RM. Feeling labeled, judged, lectured, and rejected by family and friends over depression: cautionary results for primary care clinicians from a multi-centered, qualitative study. BMC Fam Pract. 2012;13:64.

3. Tucker JR, Hammer JH, Vogel DL, Bitman RL, Wade NG, Maier EJ. Disentangling self-stigma: are mental illness and help-seeking selfstigmas different? J Couns Psychol. 2013;60:520-531.

4. Halter MJ. The stigma of seeking care and depression. Arch Psychiatr Nurs. 2004;18:178-184.

5. Fung KM, Tsang HW, Chan F. Self-stigma, stages of change and psychosocial treatment adherence among Chinese people with schizophrenia: a path analysis. Soc Psychiatry Psychiatr Epidemiol. 2010;45: 561-568.

6. Prasko J, Mainerova B, Diveky T, et al. [Panic disorder and stigmatization]. Act Nerv Super Rediviva. 2011;53:194-201. Czech.

7. Latalova K, Ociskova M, Prasko J, Kamaradova D, Jelenova D, Sedlackova Z. Self-stigmatization in patients with bipolar disorder. Neuro Endocrinol Lett. 2013;34:265-272.

8. Hoerster KD, Malte CA, Imel ZE, Ahmad Z, Hunt SC, Jakupcak M. Association of perceived barriers with prospective use of VA mental health care among Iraq and Afghanistan veterans. Psychiatr Serv. 2012;63:380-382.

9. Zinzow HM, Britt TW, McFadden AC, Burnette CM, Gillispie S. Connecting active duty and returning veterans to mental health treatment: interventions and treatment adaptations that may reduce barriers to care. Clin Psychol Rev. 2012;32:741-753.

10. Conner KO, Copeland VC, Grote NK, et al. Mental health treatment seeking among older adults with depression: the impact of stigma and race. Am J Geriatr Psychiatry. 2010;18:531-543.

11. Hammer JH, Vogel DL, Heimerdinger-Edwards SR. Men's help seeking: examination of differences across community size, education, and income. Psychol Men Masc. 2012. [Epub ahead of print].

12. Vogel DL, Heimerdinger-Edwards SR, Hammer JH, Hubbard A. "Boys don't cry": examination of the links between endorsement of masculine norms, self-stigma, and help-seeking attitudes for men from diverse backgrounds. J Couns Psychol. 2011;58:368-382.

13. Marcelli D. [The difference between the sexes, a question of physiology or culture]? Revue Adolescence. 2007;25:321-339. French.

14. Phillips DA. Reproducing normative and marginalized masculinities: adolescent male popularity and the outcast. Nurs Inq. 2005;12: 219-230.

15. Vogel DL, Wade NG, Hackler AH. Perceived public stigma and the willingness to seek counseling: the mediating roles of self-stigma and attitudes toward counseling. J Couns Psychol. 2007;54:40-50.

16. Judd F, Jackson H, Komiti A, Murray G, Fraser C. Service utilisation by rural residents with mental health problems. Australas Psychiatry. 2007; $15: 185-190$

17. Crisp AH, Gelder MG, Rix S, Meltzer HI, Rowlands OJ. Stigmatisation of people with mental illnesses. Br J Psychiatry. 2000;177:4-7.

18. Link BG. Understanding labeling effects in the area of mental disorders: an assessment of the effects of expectation of rejection. Am Sociol Rev. 1987;52:96-112.
19. Griffiths KM, Christensen H, Jorm AF, Evans K, Groves C. Effect of web-based depression literacy and cognitive-behavioural therapy interventions on stigmatising attitudes to depression: randomised controlled trial. Br J Psychiatry. 2004;185:342-349.

20. Ritsher JB, Otilingam PG, Grajales M. Internalized stigma of mental illness: psychometric properties of a new measure. Psychiatry Res. 2003; 121:31-49.

21. Vogel DL, Wade NG, Haake S. Measuring the self-stigma associated with seeking psychological help. J Couns Psychol. 2006;53:325-337.

22. Gitlin LN, Chernett NL, Dennis MP, Hauck WW. Identification of and beliefs about depressive symptoms and preferred treatment approaches among community-living older African Americans. Am J Geriatr Psychiatry. 2012;20:973-984.

23. Wang J, Fick G, Adair C, Lai D. Gender specific correlates of stigma toward depression in a Canadian general population sample. J Affect Disord. 2007;103:91-97.

24. Brohan E, Elgie R, Sartorius N, Thornicroft G. Self-stigma, empowerment and perceived discrimination among people with schizophrenia in 14 European countries: the GAMIAN-Europe study. Schizophr Res. 2010;122:232-238.

25. Girma E, Tesfaye M, Froeschl G, Moller-Leimkuhler AM, Dehning S, Muller N. Facility based cross-sectional study of self stigma among people with mental illness: towards patient empowerment approach. Int J Ment Health Syst. 2013;7:21

26. Yen CF, Chen CC, Lee Y, Tang TC, Yen JY, Ko CH. Self-stigma and its correlates among outpatients with depressive disorders. Psychiatr Serv. 2005;56:599-601.

27. Ward EC, Wiltshire JC, Detry MA, Brown RL. African-American men and women's attitude toward mental illness, perceptions of stigma, and preferred coping behaviors. Nurs Res. 2013;62:185-194.

28. Mackenzie CS, Knox VJ, Gekoski WJ, Macaulay HL. An adaptation and extension of the attitudes toward seeking professional psychological help scale. J Appl Soc Psychol. 2004;34:2410-2435.

29. Pescosolido BA, Medina TR, Martin JK, Long JS. The "backbone" of stigma: identifying the global core of public prejudice associated with mental illness. Am J Public Health. 2013;103:853-860.

30. Corrigan PW, Watson AC. Understanding the impact of stigma on people with mental illness. World Psychiatry. 2002;1:16-20.

31. Livingston JD, Boyd JE. Correlates and consequences of internalized stigma for people living with mental illness: a systematic review and meta-analysis. Soc Sci Med. 2010;71:2150-2161.

32. Ritsher JB, Phelan JC. Internalized stigma predicts erosion of morale among psychiatric outpatients. Psychiatry Res. 2004;129:257-265.

33. Link BG, Cullen FT, Frank J, Wozniak JF. The social rejection of former mental patients: understanding why labels matter. Am J Sociol. 1987;92:1461-1500.

34. Pederson EL, Vogel DL. Male gender role conflict and willingness to seek counseling: testing a mediation model on college-aged men. J Couns Psychol. 2007;54:373-384.

35. Levant RF, Stefanov DG, Rankin TJ, Halter MJ, Mellinger C, Williams CM. Moderated path analysis of the relationships between masculinity and men's attitudes toward seeking psychological help. J Couns Psychol. 2013;60:392-406.

36. Johnson JL, Oliffe JL, Kelly MT, Galdas P, Ogrodniczuk JS. Men's discourses of help-seeking in the context of depression. Sociol Health Illn. 2012;34:345-361.
Neuropsychiatric Disease and Treatment

\section{Publish your work in this journal}

Neuropsychiatric Disease and Treatment is an international, peerreviewed journal of clinical therapeutics and pharmacology focusing on concise rapid reporting of clinical or pre-clinical studies on a range of neuropsychiatric and neurological disorders. This journa is indexed on PubMed Central, the 'PsycINFO' database and CAS,

\section{Dovepress}

and is the official journal of The International Neuropsychiatric Association (INA). The manuscript management system is completely online and includes a very quick and fair peer-review system, which is all easy to use. Visit http://www.dovepress.com/testimonials.php to read real quotes from published authors. 